\title{
COMPARATIVE ASSESSMENT OF THE AREA OF SEALER VOIDS IN SINGLE-CONE OBTURATION DONE WITH ENDOSEAL MTA, AH PLUS AND PULPDENT SEALER
}

\author{
Vidhi Soni1, Vasundhara Shivanna2, Prakash Lokhande 3
}

1Final Year Postgraduate Student, Department of Conservative Dentistry and Endodontics, College of Dental Sciences, Davanagere, Karnataka, India.

${ }_{2}^{2}$ HOD and Professor, Department of Conservative Dentistry and Endodontics, College of Dental Sciences, Davanagere, Karnataka, India. ${ }_{3}^{3}$ Reader, Department of Conservative Dentistry and Endodontics, College of Dental Sciences, Davanagere, Karnataka, India.

\section{ABSTRACT}

\section{BACKGROUND}

Obturation voids have a potential to allow leakage through the sealer mass. Single cone obturation technique is more prone to have voids, as the volume of sealer used is larger as compared to other techniques.

Aim- To compare the area of voids in Endoseal MTA, pulpdent and AH Plus sealers when employed with SC obturation technique.

\section{MATERIALS AND METHODS}

This is a randomised controlled study. Forty-five teeth were cleaned, shaped and divided into three groups for SC obturation using Endoseal MTA, AH Plus and pulpdent sealers, respectively. Teeth were sectioned at apical, middle and coronal third. Stereomicroscope, digital image and image software were used to assess the area of sealer voids. SPSS software and Kruskal-Wallis and Mann-Whitney tests were used to analyse the results.

\section{RESULTS}

The three tested sealers showed voids in all the sections except Endoseal, which was void free in apical and middle sections. There were significant differences between these sealers regarding their section wise area of voids $(\mathrm{P}<0.05)$. Similarly, Endoseal MTA showed the least overall area of voids followed by AH Plus and there were significant differences in their overall mean area of voids $(\mathrm{P}<0.05)$.

\section{CONCLUSION}

SC obturation with Endoseal MTA, which showed void free apical and middle-third sections had significantly least area of voids in the sealer followed by the one with AH Plus sealer, whereas pulpdent sealers showed maximum area of voids.

\section{KEY WORDS}

AH Plus, Endoseal MTA, Pulpdent, Root Canal Sealer, Single Cone Obturation, Voids.

HOW TO CITE THIS ARTICLE: Soni V, Shivanna V, Lokhande P. Comparative assessment of the area of sealer voids in single-cone obturation done with Endoseal MTA, AH plus and pulpdent sealer. J. Evolution Med. Dent. Sci. 2018;7(32):3610-3613, DOI: $10.14260 /$ jemds $/ 2018 / 810$

\section{BACKGROUND}

Main objective of root canal treatment is to achieve a threedimensional obturation. Various techniques are used for this purpose, which uses the core material and root canal sealer.[1,2] Single cone obturation technique brought the revolutionary change by using a single well-fitting guttapercha cone with the sealer.[3] Nickel titanium instrument having a greater taper corresponding to the gutta-percha facilitate the use of single cone obturation technique. ${ }^{[4]}$ As the gutta-percha is solid core obturating material, voids are more commonly seen in the sealer mass or at the interface with the sealer which allows the passage of toxin to pass into the periapex and decreases the quality of obturation. ${ }^{[3,5,6]}$ Voids are critically found more in SC obturation technique as

'Financial or Other Competing Interest': None.

Submission 15-06-2018, Peer Review 24-07-2018,

Acceptance 30-07-2018, Published 06-08-2018.

Corresponding Author:

Dr. Vidhi Soni,

Room No. 9

B-Block,

College of Dental Sciences,

Davangere, Karnataka, India.

E-mail: vidhi4588@gmail.com

DOI: $10.14260 /$ jemds $/ 2018 / 810$ compared to other technique, because volume of sealer used is more in SC obturation technique. [3] Therefore, it is very important to quantify that sealer used in single cone obturation (SC) technique should have minimum or less number of voids. [7]

Many root canal sealers are available based on chemical composition such as calcium hydroxide-based, zinc oxide eugenol-based, resin-based sealer and mineral trioxide aggregate based. Mineral Trioxide Aggregates (MTA) based calcium silicate cement is gaining popularity during root canal obturation due to its bioactive characteristic to form an apatite in dentinal tubules. ${ }^{[8]}$ It is also believed that MTA when come in contact with soft tissue dissolve into calcium hydroxide. Recently new Pozzolan-based MTA sealer cement known as Endoseal MTA, (Maruchi) have been introduced. This Endoseal MTA is calcium-silicate based with a chemical composition very similar to that of MTA.[9] Endoseal is known for its intratubular biomineralization, high radiopacity, low solubility in contact with tissue fluids and expansion during setting and excellent viscosity for insertion. ${ }^{[8,10]}$ Studies have shown that it has favourable mechanical characteristics, biocompatibility, mineralization potential and odontogenic effects of the pozzolan cement. ${ }^{[8]}$

There are only few studies available which have evaluated and compared the presence of voids within the 
sealer mass, particularly Endoseal sealers when employed with SC technique.[11] Therefore, this study was conducted for comparative evaluation of the area of voids in Endoseal MTA, resin and zinc oxide-eugenol-based sealers when employed with SC obturation technique.

\section{MATERIALS AND METHODS}

\section{Method of Collection of Data}

This is a randomised controlled study. In this study, forty-five natural human single-rooted mandibular premolar teeth extracted for periodontal or orthodontic reasons were used to obtain samples. Sample size has been taken conveniently. Allocation is done using computer generated table. Exclusive criteria for this study are broken teeth, carious teeth, teeth with internal or external resorption and teeth with hypoplasia.

After the teeth have been selected, access opening was prepared and working length was determined by inserting a No. $15 \mathrm{~K}$ file into the canal until the tip of the file was visible at the apical foramen. Pro-Taper (Dentsply Maillefer, Ballaigues, Switzerland) Ni-Ti rotary files were used for cleaning and shaping using crown down technique upto size F3. Irrigation was done using sodium hypochlorite (5.25\%) throughout the preparation followed by $17 \%$ ethylenediaminetetraacetic acid solution to remove the smear layer and saline as the final irrigant. The prepared teeth were randomly divided into three groups with fifteen teeth in each group, for SC obturation using calcium silicate-based Endoseal MTA, Epoxy resin-based AH Plus (Dentsply, USA) and zinc oxide-eugenol-based Pulpdent (Pulpdent Corporation, MA, USA) sealers, respectively.

Lentulospiral (Dentsply Maillefer, Ballaigues, Switzerland) were used to apply the sealer into the canal wall which were mixed according to the manufacturer's instructions. After coating the selected Gutta-percha cone, which is corresponding to F3, sized Pro-Taper (Dentsply, Switzerland) with a sealer, gutta-percha cone were inserted into the canal and the excess portion was cut-off until the cervical line. Using SC technique each group was obturated using their respective root canal sealers. The entire obturated specimen were stored in $100 \%$ relative humidity at $37^{\circ}$ for 7 days to ensure complete setting of the sealers. Later, the decoronation of obturated teeth were done at the cementoenamel junction and the roots were marked with shallow cuts on the buccal and lingual aspects at an approximate level of $1 \mathrm{~mm}, 4 \mathrm{~mm}, 8 \mathrm{~mm}$ and $12 \mathrm{~mm}$ from their apices using a diamond disc. Using a chisel, roots were sectioned through the marked cuts to obtain the apical, middle and coronal third sections. Thickness of each section were approximately of $3 \pm 0.5 \mathrm{~mm}$ and a total of 15 sectioned samples were obtained in each group.

A stereomicroscope (Zeiss, Thornwood, NY, USA) with a magnification $\times 40$ was used to observe each section and digital images were taken. To calculate the area of voids, images were analysed using the Image software (National Institutes of Health, Bethesda, MD, USA). Statistical analysis was done using SPSS software (version 15, SPSS Inc., Chicago, IL, USA) and Kruskal-Wallis and Mann-Whitney tests.
RESULTS

\begin{tabular}{|c|c|c|c|c|c|c|}
\hline & & & Q1 & Median & Q3 & P-value \\
\hline \multirow{3}{*}{ AH Plus } & Apical & 15 & 0.003 & 0.005 & 0.007 & \\
\cline { 2 - 6 } & Middle & 15 & 0.0011 & 0.007 & 0.009 & \multirow{4}{*}{0.000} \\
\cline { 2 - 6 } & Coronal & 15 & 0.019 & 0.022 & 0.026 & \\
\hline \multirow{3}{*}{ MTA } & Apical & 15 & 0 & 0 & & \multirow{4}{*}{0.000} \\
\cline { 2 - 6 } & Middle & 15 & 0 & 0 & & \multirow{4}{*}{0.000} \\
\cline { 2 - 6 } & Coronal & 15 & 0.008 & 0.0084 & & \\
\hline \multirow{3}{*}{ Pulpdent } & Apical & 15 & 0.013 & 0.017 & & \\
\cline { 2 - 5 } & Middle & 15 & 0.033 & 0.037 & \\
\cline { 2 - 5 } & Coronal & 15 & 0.03 & 0.034 & 0.038 & \\
\hline \multirow{2}{*}{ Table 1. Section-Wise Mean Area of Voids (mm2) in the } \\
study group with Median and IQR \\
\hline
\end{tabular}

\begin{tabular}{|c|c|c|c|c|}
\hline Groups & & Q1 & Median & Q3 \\
\hline AH Plus & 45 & 0.0045 & 0.008 & 0.0195 \\
\hline MTA & 45 & 0 & 0 & 0.0081 \\
\hline Pulpdent & 45 & 0.0195 & 0.032 & 0.0375 \\
\hline
\end{tabular}

Table 2. Overall Mean Area of Voids (mm2) in the study groups with a Median and IQR

\begin{tabular}{|c|c|c|c|c|c|}
\hline Group & N & Mean & $\begin{array}{c}\text { Standard } \\
\text { Deviation }\end{array}$ & $\begin{array}{c}\text { Kruskal- } \\
\text { Wallis } \\
\text { Chi-square }\end{array}$ & P-value \\
\hline MTA & 45 & .0027 & .00389 & & \\
\cline { 1 - 4 } AH Plus & 45 & .0113 & .00917 & \multirow{2}{*}{87.231} & .000 \\
\hline Pulpdent & 45 & .0288 & .01071 & \\
\cline { 1 - 3 }
\end{tabular}

Table 3. Statistical differences in the overall Mean Area of Voids between the Study Groups

\section{DISCUSSION}

In this study, Nickel-Titanium rotary instruments were used due to its easy availability of gutta-percha with corresponding taper of $\mathrm{Ni}$-Ti rotary files and also it reduces the time required for preparation as compared to other techniques. Although, it has become a very popular technique, it has some of the disadvantages like inadequate adaptation of gutta-percha in oval, irregular and complex canal and limited penetration of spreader for any further lateral compaction. ${ }^{[3,4]}$ Therefore, in single cone obturation technique sealer and its sufficient volume play a very important role in providing a hermetic seal.

In single cone obturation technique, there is greater interaction of single master cone with the sealer to provide an adequate seal and also volume of sealer used is larger as compared to other and thus it can be said that there is increased chance of voids in SC obturation technique as compared to other techniques and these voids are very critical in apical region, because it plays an important role in success of any root canal treatment, therefore in this study area of sealer voids after SC obturation is evaluated.[3,12]

Various factors that causes voids formation are due to air entrapment during mixing or carrying and coating the sealer to the canal wall and inherent factors such as sealer manipulation and handling as well as properties such as flow and density of the sealer.[1,2]

In this study zinc oxide-based sealer (Pulpdent) was employed, because it is considered to be the most conventional sealer along with it satisfactory physicochemical properties.[1] Epoxy resin based sealer $(\mathrm{AH}$ Plus) was used because of its excellent properties such as low solubility, small expansion, adhesion to dentin and very good sealing ability.[13] A calcium silicate-based sealer (Endoseal MTA) was studied, as it is a newly introduced sealer and 
though it is claimed to have many favourable properties and biocompatibility, but the occurrence of voids in this sealer had not been evaluated by previous studies. [9,12]

Various techniques have been used to evaluate the area of sealer voids.[11] However, in this study stereomicroscopic examination and digital image analysis with software was employed to assess the voids. Though it has disadvantages such as structural loss or destruction of samples during sectioning, but it has many advantages such as three-dimensional view of the surface to be examined. No pre-treatment of specimen and also associated with image analysis software, which eliminates human errors during the interpretation of the parameters. ${ }^{[7,11]}$

In this study, apical section of all the groups showed either no voids or lesser area of voids as compared to middle and coronal section due to the close and maximal fit of the single gutta-percha master cone apically.[14] And also in previous studies, it has been shown that single cone obturation have a good apical seal as compared to coronal, while the middle portion showed the least volume percentage because it is said that more hydraulic force is generated when the greater taper SC close fit to the apical portion and increases the flow in the apical portion by mean of shear thinning mechanism and this will probably cause collapse of air bubbles or air entrapment under pressure and enhance the flow of sealer and lead to lesser or no voids in the apical sections. But when the SC is pushed into the canal, some of the excess sealers backflows in the middle and coronal portion.[15,16] This could possibly be the reason for air entrapment and may explain the occurrence of more voids in middle or coronal sections than apical one.

In this study, SC obturation with Endoseal MTA and AH Plus sealers showed significantly better results than those with Pulpdent sealer. The occurrence of voids in a sealer can be attributed to its manipulative and handling properties and also from the rheological properties of a sealer.[12] Flow helps the sealer to penetrate better into the irregularities and the accessory canals, which is generally related with the particle size and composition of the sealer and because of their better flow property significant difference was seen when Endoseal MTA and AH Plus sealer was compared with the pulpdent sealer.[9] Further Endoseal MTA is available in premixed injectable paste form and $\mathrm{AH}$ Plus sealer is paste/ paste system available in the form of two paste system also contribute to their better flow as compared to pulpdent sealer, which is a regular zinc oxide-eugenol-based powder/liquid formulation. ${ }^{9,13]}$

When the Endoseal MTA and AH Plus sealer were compared, though there was no significant difference seen in the critical apical section, but the Endoseal MTA showed the void free apical and middle portion section as compared to $\mathrm{AH}$ plus sealer. This can be due to its particle size and setting mechanism of Endoseal MTA. Endoseal MTA is a pozzolan based cement having particle size of 1.5 micro-meter, whereas AH plus has a particle size of 8 micro-meter.[8,13] Endoseal MTA, because of its particle size becomes thixotropic when the material is released via needle tip which infiltrates into dentinal tubules to form sealer tags and apatite precursors, which helps in intra-tubular biomineralization. ${ }^{[8]}$ Endoseal MTA undergoes setting expansion due to presence of MTA, which enhances the sealing ability and makes the sealer void free in apical and middle portion, its setting causes hydration of anhydrous mineral oxide to form calcium silicate hydrate and calcium hydroxide compound which leads to expansion. ${ }^{[9,12]}$ Therefore, Endoseal MTA sealer apart from its good flow and favourable properties has setting expansion mechanism and high alkalinity ( $\mathrm{pH}$ 10-11), which provides several biological advantages like alkalization which promotes healing and hard tissue formation.[9] Thus, co-relating the findings from this study, despite AH Plus having minimum shrinkage, Endoseal MTA would have a distinct advantage over AH Plus sealer in promoting superior sealing with SC technique of obturation. $[6,8,9]$ However studies, which are employing the large sample size, assist to further validate the results of this study by using micro-computed tomography and calculating the percentage of voids in relation to the total area of each canal section or the whole canal.

\section{Limitations}

In this study sample size was small, because of short study period.

\section{CONCLUSION}

Within the limitations of this study, it can be concluded that the SC obturation with Endoseal MTA sealer had no voids in the apical and middle-third sections and had least overall mean area of voids. The differences were significant when compared to those with AH Plus and Pulpdent sealers. SC obturation with AH Plus sealer also showed significantly lesser area of voids in the apical and middle sections and lesser overall mean area of voids when compared to those with Pulpdent sealer.

\section{REFERENCES}

[1] Kumar RV, Shruthi C. Evaluation of the sealing ability of resin cement used as a root canal sealer: an in vitro study. J Conserve Dent 2012;15(3):274-7.

[2] Dalat DM, Spångberg LS. Comparison of apical leakage in root canals obturated with various Gutta percha techniques using a dye vacuum tracing method. J Endod 1994;20(7):315-9.

[3] Wu MK, Bud MG, Wesselink PR. The quality of single cone and laterally compacted Gutta-percha fillings in small and curved root canals as evidenced by bidirectional radiographs and fluid transport measurements. Oral Surg Oral Med Oral Pathol Oral Radiol Endod 2009;108(6):946-51.

[4] Bal AS, Hicks ML, Barnett F. Comparison of laterally condensed 0.06 and 0.02 tapered Gutta-percha and sealer in vitro. J Endod 2001;27:786-8.

[5] Epley SR, Fleischman J, Hartwell G, et al. Completeness of root canal obturations: Epiphany techniques versus Gutta-percha techniques. J Endod 2006;32(6):541-4.

[6] Johnson JD. Root canal filling materials. In: Ingle JI, Bakland LK, Baumgartner JC, eds. Ingle's Endodontics. Hamilton, Ontario: BC Decker Inc., 2008: p. 1019-52.

[7] Anantula K, Ganta AK. Evaluation and comparison of sealing ability of three differnt obturation techniqeslateral condensation, obtura II, GuttaFlow: an in vitro study. J Conserv Dent 2011;14(1):57-61. 


\section{Jemds.com}

[8] Yoo YJ, Baek SH, Kum KY, et al. Dynamic intratubular biomineralization following root canal obturation with pozzolan-based mineral trioxide aggregate sealer cement. Scanning 2016;38(1):50-6.

[9] Lim ES, Park YB, Kwon YS, et al. Physical properties and biocompatibility of an injectable calcium-silicatebased root canal sealer: in vitro and in vivo study. BMC Oral Health 2015;15:129.

[10] Sagsen B, Ustün Y, Pala K, et al. Resistance to fracture of roots filled with different sealers. Dent Mater J 2012;31(4):528-32.

[11] Mutal L, Gani O. Presence of pores and vacuoles in set endodontic sealers. Int Endod J 2005;38(10):690-6.

[12] Gomes-Filho JE, Moreira JV, Watanabe S, et al. Sealability of MTA and calcium hydroxide containing sealers. J Appl Oral Sci 2012;20(3):347-51.

\section{Original Research Article}

[13] Tyagi S, Mishra P, Tyagi P. Evolution of root canal sealers: an insight story. European Journal of General Dentistry 2013;2(3):199-218.

[14] Obeidat RS, Abdallah H. Radiographic evaluation of the quality of root canal obturation of single-matched cone Gutta-percha root canal filling versus hot lateral technique. Saudi Endod J 2014;4(2):58-63.

[15] Crasta SA, Nanjundasetty JK, Panuganti V, et al. Volumetric analysis of root canals obturated with cold lateral condensation, single-cone and thermoplasticized Gutta-percha techniques using spiral computed tomography: an in vitro study. Saudi Endod J 2014;4(2):64-9.

[16] Anusavice KJ, Shen C, Rawls HR. Phillips' science of dental materials. $12^{\text {th }}$ edn. St. Louis, Missouri: Elsevier Saunders 2013. 